Stud. Univ. Babeş-Bolyai Math. 66(2021), No. 1, 139-158

DOI: 10.24193/subbmath.2021.1.13

\title{
Split equality variational inequality problems for pseudomonotone mappings in Banach spaces
}

\author{
Oganeditse A. Boikanyo and Habtu Zegeye
}

Dedicated to Professor Gheorghe Moroşanu on the occasion of his 70th anniversary.

\begin{abstract}
A new algorithm for approximating solutions of the split equality variational inequality problems (SEVIP) for pseudomonotone mappings in the setting of Banach spaces is introduced. Strong convergence of the sequence generated by the proposed algorithm to a solution of the SEVIP is then derived without assuming the Lipschitz continuity of the underlying mappings and without prior knowledge of operator norms of the bounded linear operators involved. In addition, we provide several applications of our method and provide a numerical example to illustrate the convergence of the proposed algorithm. Our results improve, consolidate and complement several results reported in the literature.
\end{abstract}

Mathematics Subject Classification (2010): 47H09, 47J20, 65K15, 47J05, 90C25.

Keywords: Pseudomonotone mapping, split equality variational inequality problem, strong convergence, variational inequality.

\section{Introduction}

Let $K$ be a nonempty, closed and convex subset of a real Hilbert space $H$, and $T: C \rightarrow H$ be a nonlinear mapping. The variational inequality problem (VIP), first introduced by Stampacchia [31] and Fichera [19] in 1964, is a problem that consist of finding an element $x \in C$ such that $\langle T x, y-x\rangle \geq 0$ for all $y \in C$. For a nonlinear mapping $T: C \rightarrow H$, we denote the solution of the VIP by $V I(C, T)$ if it is nonempty. It is known that $x$ solves the VIP if and only if $x$ is a fixed point of the map $P_{C}(I-\lambda T): C \rightarrow C$. Variational inequality problems have been studied extensively by several authors, thanks to their relevance in various applications in areas such as mechanics, physics, engineering, convex programming and control theory. Among these studies, VIPs for continuous and pseudomonotone maps will be of particular interest to us. Let us remember that if $T$ is continuous and pseudomonotone, then $V I(C, T)$ is closed and convex [26]. In $[30,33,34]$, the authors studied algorithms for 
solving uniformly continuous and weakly sequentially continuous pseudomonotone VIPs in Hilbert spaces. The distinctive feature of the algorithms constructed and analyzed in $[33,34]$ is mainly on the different Armijo-type line search rules used. For further reading on the VIP, particularly iterative methods for finding solutions of VIPs, the interested reader is referred to articles [2, 7, 10, 21-23, 25, 29, 38, 41], and their references.

Let $K_{1}$ and $K_{2}$ be nonempty, closed and convex subsets of real Hilbert spaces $H_{1}$ and $H_{2}$, respectively. Also let $A: H_{1} \rightarrow H_{3}$ and $B: H_{2} \rightarrow H_{3}$ be bounded linear mappings, where $H_{3}$ is another real Hilbert space. Consider two nonlinear mappings $T: H_{1} \rightarrow H_{1}$ and $S: H_{2} \rightarrow H_{2}$. The split equality variational inequality problem (SEVIP) is formulated as a problem of finding:

$$
(x, y) \in K_{1} \times K_{2} \text { such that }(x, y) \in V I\left(K_{1}, T\right) \times V I\left(K_{2}, S\right) \text { and } A x=B y .
$$

The SEVIP is quite general and it includes as special cases, split equality zero point problem (see, [18]), common solutions of the variational inequality problem [12], common zeros of mappings [16], split equality feasibility problem [27], has been studied extensively by many authors and applied to solving many real life problems such as in modelling intensity-modulated radiation therapy treatment planning [8,9], modelling of inverse problems arising from phase retrieval, and in sensor networks in computerised tomography and data compression $[5,17]$.

If, in (1.1), we consider $H_{2}=H_{3}$, and $B=I$, the identity mapping on $H_{2}$, the SEVIP reduces to the split varitional inequality problem (SVIP) that was recently introduced by Censor et al. [10]. The SVIP consists of finding:

$$
(x, y) \in K_{1} \times K_{2} \text { such that }(x, y) \in V I\left(K_{1}, T\right) \times V I\left(K_{2}, S\right) \text { and } y=A x,
$$

that is, the SVIP constitutes a pair of VIPs, which have to be solved so that the image $y=A x$, under a given bounded linear operator $A$ of the solution $x$ of the VIP in $H_{1}$, is a solution of another VIP in another space $H_{2}$. In Moudafi [27], it was noted that the SVIP generalizes the split fixed point problem, split variational inequality problem, split zero point problem and split feasibility problem (see also [3, 4, 6, 13-15, 35, 40], and the references therein). Many of the results cited above were obtained in the setting of real Hilbert spaces. In [11], Censor et al. studied an iterative algorithm that approximates a solution of the SVIP for a monotone mapping in Hilbert spaces and proved weak convergence results of the algorithm. In [6], Byrne et al. constructed a scheme which approximates the solution of the SVIP for monotone type mappings in Hilbert spaces and proved weak and strong convergence results of the scheme under certain assumptions.

Motivated by the work of Censor et al. [11], Byrne et al. [6] and Thong et al [33], we introduce and study a new algorithm for solving the SEVIP for uniformly continuous and weakly sequentially continuous pseudomonotone mappings in the setting of Banach spaces. Strong convergence of the proposed algorithm is proved under mild assumptions and without prior knowledge of operator norms of bounded linear mappings involved. Some applications of the main results are also provided. A numerical example is given to illustrate the convergence of the proposed algorithm. Our results improve, consolidate and complement several results in the literature. 


\section{Preliminaries}

Let $E$ be a reflexive, strictly convex and smooth Banach space and let $C$ be a nonempty, closed and convex subset of $E$. Consider the function $\phi: E \times E \rightarrow \mathbb{R}$, introduced by Alber [1], defined by

$$
\phi(y, x)=\|y\|^{2}-2\langle y, J x\rangle+\|x\|^{2}, \text { for } x, y \in E,
$$

where $J: E \rightarrow E^{*}$ is the normalized duality mapping defined by

$$
J x:=\left\{x^{*} \in E^{*}:\left\langle x, x^{*}\right\rangle=\|x\|^{2},\|x\|=\left\|x^{*}\right\|\right\}, \forall x \in E .
$$

It is known that if $E$ is uniformly smooth, then $J$ is uniformly norm to norm continuous on each bounded subset of $E$ (see, [32]). Furthermore, if $E$ is a reflexive and strictly convex Banach space with a strictly convex dual, then $J^{-1}$ is a duality mapping from $E^{*}$ into $E$ which satisfies $J J^{-1}=I_{E^{*}}$ and $J^{-1} J=I_{E}$ (see, [32]). The generalized projection mapping, introduced by Alber [1], is a mapping $\Pi_{C}: E \rightarrow C$ that assigns an arbitrary point $x \in E$ to the minimizer, $\bar{x}$, of $\phi(., x)$ over $C$.

Lemma 2.1. [1] Let $C$ be a nonempty, closed and convex subset of a real reflexive, strictly convex, and smooth Banach space $E$ and let $x \in E$. Then $\phi\left(y, \Pi_{C} x\right)+$ $\phi\left(\Pi_{C} x, x\right) \leq \phi(y, x)$ for all $y \in C$.

Lemma 2.2. [20] Let $E$ be a real smooth and uniformly convex Banach space and let $\left(x_{n}\right)$ and $\left(y_{n}\right)$ be two sequences in E. If either $\left(x_{n}\right)$ or $\left(y_{n}\right)$ is bounded and $\phi\left(x_{n}, y_{n}\right) \rightarrow$ 0 as $n \rightarrow \infty$, then $x_{n}-y_{n} \rightarrow 0$, as $n \rightarrow \infty$.

Lemma 2.3. [1] Let $C$ be a convex subset of a real smooth Banach space E. Let $x \in E$. Then $x_{0}=\Pi_{C} x$ if and only if $\left\langle z-x_{0}, J_{E} x-J_{E} x_{0}\right\rangle \leq 0, \forall z \in C$.

Consider the function $V: E \times E^{*} \rightarrow \mathbb{R}$, studied by Alber [1], defined by

$$
V\left(x, x^{*}\right)=\|x\|^{2}-2\left\langle x, x^{*}\right\rangle+\left\|x^{*}\right\|^{2}, \text { for all } x \in E \text { and } x^{*} \in E^{*} .
$$

Lemma 2.4. [1] Let $E$ be reflexive, strictly convex and smooth Banach space with $E^{*}$ as its dual. Then for all $x \in E$ and $x^{*}, y^{*} \in E^{*}$,

$$
V\left(x, x^{*}\right)+2\left\langle J_{E}^{-1} x^{*}-x, y^{*}\right\rangle \leq V\left(x, x^{*}+y^{*}\right) .
$$

Lemma 2.5. [28] If $E$ is a smooth Banach space and $\left\{t_{i}\right\} \in(0,1)$ with $\sum_{i=1}^{N} t_{i}=1$, then

$$
\phi\left(z, J_{E}^{-1}\left(\sum_{i=1}^{N} t_{i} J_{E} x_{i}\right)\right) \leq \sum_{i=1}^{N} t_{i} \phi\left(z, x_{i}\right) .
$$

Lemma 2.6. [37] Let $\left(a_{n}\right)$ be a sequence of nonnegative real numbers such that $a_{n+1} \leq$ $\left(1-\beta_{n}\right) a_{n}+\beta_{n} \delta_{n}$, for all $n \geq 1$, where $\left(\beta_{n}\right) \subset(0,1)$ and $\left(\delta_{n}\right) \subset R$ satisfying $\sum_{n=1}^{\infty} \beta_{n}=\infty$, and $\limsup _{n \rightarrow \infty} \delta_{n} \leq 0$. Then, $\lim _{n \rightarrow \infty} a_{n}=0$.

Lemma 2.7. [24] Let $\left(a_{n}\right)$ be a sequence of real numbers such that there exists a subsequence $\left(n_{i}\right)$ of $(n)$ such that $a_{n_{i}}<a_{n_{i}+1}$ for all $i \in \mathbb{N}$. Then there exists $a$ nondecreasing sequence $\left(m_{k}\right) \subset \mathbb{N}$ such that $m_{k} \rightarrow \infty$ and $\max \left\{a_{m_{k}}, a_{k}\right\} \leq a_{m_{k}+1}$. In fact, $m_{k}=\max \left\{j \leq k: a_{j}<a_{j+1}\right\}$. 
Lemma 2.8. [39] Let $E$ be a reflexive and smooth real Banach space. Then, there exists $\alpha>0$ such that $\left\langle x-y, J_{E} x-J_{E} y\right\rangle \geq \alpha\|x-y\|^{2}$ for all $x, y \in E$.

Lemma 2.9. [36] Let $E$ be a reflexive and smooth real Banach space. Then for each $x, y \in E$, we have $\phi(y, x) \geq \frac{1}{2}\|x-y\|^{2}$.

Lemma 2.10. Let $C$ be a closed and convex set in a reflexive real Banach space $E, h$ be a real-valued function on $E$, and $K$ be the set $\{x \in C: h(x) \leq 0\}$. If $K$ is nonempty and $h$ is Lipschitz continuous on $C$ with constant $L>0$, then

$$
\phi\left(x, \Pi_{K} x\right) \geq \frac{1}{2 L^{2}}(h(x))^{2}, \text { for all } x \in C .
$$

Proof. Clearly (2.2) holds for all $x \in K$. Hence, it suffices to show that (2.2) holds for every $x \in C \backslash K$. Let $x \in C$ but $x \notin K$. Since $K$ is closed, there exists $y \in K$ such that $\phi(x, y)=\phi\left(x, \Pi_{K} x\right)$. It follows from the Lipschitz continuity of $h$ that $|h(x)-h(y)| \leq L\|x-y\|$. Since $x \notin K$ and $y \in K$, we have $h(x)>0$ and $h(y) \leq 0$. Thus, from Lemma 2.9, we have

$$
h(x) \leq h(x)-h(y)=|h(x)-h(y)| \leq L|| x-y|| \leq L\left(2 \phi\left(x, \Pi_{K} x\right)\right)^{\frac{1}{2}},
$$

and hence the conclusion follows.

Definition 2.11. Let $T: C \rightarrow E^{*}$ be a mapping. Then $T$ is called

(a) sequentially weakly continuous on $C$ if for each sequence $\left(x_{n}\right) \subseteq C$ converging weakly to $x \in C$, the sequence $\left(A x_{n}\right)$ converges weakly to $A x$;

(b) monotone if $\langle x-y, T x-T y\rangle \geq 0$ for each $x, y \in C$;

(c) pseudomonotone on $C$ if for all $x, y \in C$,

$$
\langle y-x, T x\rangle \geq 0 \quad \text { implies }\langle y-x, T y\rangle \geq 0 .
$$

Remark 2.12. In [30], Shehu et al. asserted that using the Monte-Carlo approach, it can be shown that the map $T: \mathbb{R}^{2} \rightarrow \mathbb{R}^{2}$ defined by

$$
T(x, y)=\left(\left[x^{2}+(y-1)^{2}\right](1+y),-x^{3}-x(y-1)^{2}\right)
$$

is pseudomonotone on $\mathbb{R}^{2}$. The correctness of this method/approach in verifying pseudomonotonicity of an operator is questionable. We claim that there could still be a pair of points, say $(x, y),(u, v) \in \mathbb{R}^{2}$, such that the implication (2.3) does not hold. Indeed, (2.3) fails to hold for a pair of points $(0,1)$ and $(-1,2)$ in $\mathbb{R}^{2}$, as shown by simple computations below

$$
\langle T(0,1),(-1,2)-(0,1)\rangle=0 \geq 0 \quad \text { and } \quad\langle T(-1,2),(-1,2)-(0,1)\rangle=-4<0 .
$$

Example 2.13. Let the map $S: \mathbb{R}^{2} \rightarrow \mathbb{R}^{2}$ be defined by

$$
S(x, y)=\left(\left[x^{2}+1+(y-1)^{2}\right](1+y),-x^{3}-x\left[1+(y-1)^{2}\right]\right) .
$$

Claim 1: $S$ is not monotone. Indeed, for the pair $(1,0)$ and $(-1,-1)$, we have

$$
\langle S(1,0)-S(-1,-1),(1,0)-(-1,-1)\rangle=-3<0 .
$$

Claim 2: $S$ is pseudomonotone. To this end, we assume that $\langle S(x, y),(u, v)-(x, y)\rangle \geq 0$ is true for each pair $(x, y),(u, v) \in \mathbb{R}^{2}$. This means that

$$
\left[x^{2}+1+(y-1)^{2}\right](1+y)(u-x)+\left[-x^{3}-x\left[1+(y-1)^{2}\right]\right](v-y) \geq 0
$$


which implies that $\left[x^{2}+1+(y-1)^{2}\right][u+u y-x-x v] \geq 0$ for all $(x, y),(u, v) \in \mathbb{R}^{2}$. Therefore, $u(1+y)-x(1+v) \geq 0$ for all $(x, y),(u, v) \in \mathbb{R}^{2}$. Since $u^{2}+1+(v-1)^{2}>0$ for any $u, v \in \mathbb{R}$, we have for any $(x, y),(u, v) \in \mathbb{R}^{2}$,

$$
\langle S(u, v),(u, v)-(x, y)\rangle=\left[u^{2}+1+(v-1)^{2}\right][u(1+y)-x(1+v)] \geq 0 .
$$

Lemma 2.14. [26] Let $K$ be a nonempty, closed and convex subset of a smooth, strictly convex and reflexive real Banach space $E$. Let $A$ be a continuous pseudomonotone mapping from $K$ into $E^{*}$. Then, $V I(K, A)$ is closed and convex, and $p \in V I(K, A)$ if and only if $\langle x-p, A x\rangle \geq 0$, for all $x \in K$.

\section{Main results}

In the sequel, we shall make use of the following assumptions:

Assumption 1:

(A1) Let $E_{1}$ and $E_{2}$ be uniformly smooth and uniformly convex real Banach spaces with dual spaces $E_{1}^{*}$ and $E_{2}^{*}$, respectively, and let $E_{3}$ be a real Banach space with dual space $E_{3}^{*}$.

(A2) Let $A: E_{1} \rightarrow E_{3}$ and $B: E_{2} \rightarrow E_{3}$ be bounded linear mappings with adjoints $A^{*}: E_{3}^{*} \rightarrow E_{1}^{*}$ and $B^{*}: E_{3}^{*} \rightarrow E_{2}^{*}$, respectively.

(A3) Let $C \subseteq E_{1}$ and $D \subseteq E_{2}$ be nonempty, closed and convex subsets.

(A4) Let $T: E_{1} \rightarrow E_{1}^{*}$ and $S: E_{2} \rightarrow E_{2}^{*}$ be uniformly continuous pseudomonotone mappings that are sequentially weakly continuous on bounded subset of $C$ and $D$, respectively.

(A5) Let $\Gamma:=\{(p, q) \in C \times D:\langle x-p, T p\rangle \geq 0, \forall x \in C,\langle y-q, S q\rangle \geq 0, \forall y \in$ $D$, and $A p=B q\} \neq \emptyset$.

\section{Assumption 2:}

(B1) Let $\xi=\min \left\{\xi_{1}, \xi_{2}\right\}$, where $\xi_{1}$ and $\xi_{2}$ are constants given in Lemma 2.8 associated with $J_{E_{1}}$ and $J_{E_{2}}$, respectively.

(B2) Let $l \in(0,1), \mu>0$ and $\lambda \in\left(0, \frac{\xi}{\mu}\right)$.

(B3) Let $\left(\alpha_{n}\right) \subset(0, e] \subset(0,1)$, for some constant $e>0$, be such that $\lim _{n \rightarrow \infty} \alpha_{n}=0$ and $\sum_{n=1}^{\infty} \alpha_{n}=\infty$.

(B4) Let $0<\gamma \leq \gamma_{n} \leq \frac{\xi\left\|A x_{n}-B y_{n}\right\|^{2}}{2\left[\left\|A^{*} J_{E_{3}}\left(A x_{n}-B y_{n}\right)\right\|^{2}+\left\|B^{*} J_{E_{3}}\left(A x_{n}-B y_{n}\right)\right\|^{2}\right]}$

for $n \in \Omega=\left\{n \in \mathbb{N}: A x_{n}-B y_{n} \neq 0\right\}$, otherwise $\gamma_{n}=\gamma>0$.

Now, we introduce our algorithm for the SEVIP.

\section{Algorithm 3.1}

For arbitrary $x_{0}, u \in C$ and $y_{0}, v \in D$, define an iterative algorithm by

1. Step 1. Compute: $u_{n}=\Pi_{C} J_{E_{1}}^{-1}\left[J_{E_{1}} x_{n}-\gamma_{n} A^{*} J_{E_{3}}\left(A x_{n}-B y_{n}\right)\right]$ and $r_{1}\left(x_{n}, u_{n}\right)=x_{n}-u_{n}$.

Compute $v_{n}=\Pi_{D} J_{E_{2}}^{-1}\left[J_{E_{2}} y_{n}+\gamma_{n} B^{*} J_{E_{3}}\left(A x_{n}-B y_{n}\right)\right]$ and $s_{1}\left(y_{n}, v_{n}\right)=y_{n}-v_{n}$.

2. Step 2. Compute: $z_{n}=\Pi_{C} J_{E_{1}}^{-1}\left[J_{E_{1}} u_{n}-\lambda T u_{n}\right]$ and $r_{2}\left(u_{n}, z_{n}\right)=u_{n}-z_{n}$.

Compute $w_{n}=\Pi_{D} J_{E_{2}}^{-1}\left[J_{E_{2}} v_{n}-\lambda S v_{n}\right]$ and $s_{2}\left(v_{n}, w_{n}\right)=v_{n}-w_{n}$. 
3. Step 3. Compute $f_{n}=u_{n}-\tau_{n} r_{2}\left(u_{n}, z_{n}\right)$, where $\tau_{n}=l^{j_{n}}$ and $j_{n}$ is the smallest non-negative integer $j$ satisfying

$$
\left\langle r_{2}\left(u_{n}, z_{n}\right), \quad T u_{n}-T\left(u_{n}-l^{j} r_{2}\left(u_{n}, z_{n}\right)\right)\right\rangle \leq \mu\left\|r_{2}\left(u_{n}, z_{n}\right)\right\|^{2}
$$

and $g_{n}=v_{n}-\kappa_{n} s_{2}\left(v_{n}, w_{n}\right)$, where $\kappa_{n}=l^{h_{n}}$ and $h_{n}$ is the smallest non-negative integer $h$ satisfying

$$
\left\langle s_{2}\left(v_{n}, w_{n}\right), \quad S v_{n}-S\left(v_{n}-l^{h} s_{2}\left(v_{n}, w_{n}\right)\right)\right\rangle \leq \mu\left\|s_{2}\left(v_{n}, w_{n}\right)\right\|^{2} .
$$

4. Step 4. Compute: $x_{n+1}=J_{E_{1}}^{-1}\left[\alpha_{n} J_{E_{1}} u+\left(1-\alpha_{n}\right) J_{E_{1}} \Pi_{C_{n}} u_{n}\right]$, where

$$
C_{n}:=\left\{x \in C:\left\langle x-f_{n}, T f_{n}\right\rangle \leq 0\right\},
$$

and $y_{n+1}=J_{E_{2}}^{-1}\left[\alpha_{n} J_{E_{2}} v+\left(1-\alpha_{n}\right) J_{E_{2}} \Pi_{D_{n}} v_{n}\right]$, where

$$
D_{n}:=\left\{y \in D:\left\langle y-g_{n}, S g_{n}\right\rangle \leq 0\right\} \text {. }
$$

5. Step 5. Set $n:=n+1$ and go to Step 1 .

Lemma 3.1. Assume that Conditions (A1) - (A5) and (B1) - (B4) are satisfied. Then, the sequences $\left(x_{n}\right)$ and $\left(y_{n}\right)$ generated by Algorithm 3.1 are well defined.

Proof. It is enough to show that the search rules in (3.1) and (3.2) are well defined, and the sets $C_{n}$ and $D_{n}$ are nonempty.

Since $l \in(0,1)$ and $T$ is continuous on $C$, it follows that

$$
\left\langle r_{2}\left(u_{n}, z_{n}\right), T u_{n}-T\left(u_{n}-l^{j} r_{2}\left(u_{n}, z_{n}\right)\right)\right\rangle \rightarrow 0, \text { as } j \rightarrow \infty .
$$

On the other hand, since $\left\|r_{2}\left(u_{n}, z_{n}\right)\right\|>0$, there exists a non-negative integer $j_{n}$ satisfying inequality (3.1). Similarly, from the continuity of the mapping $S$ on $D$, there exists a non-negative integer $h_{n}$ satisfying inequality (3.2).

Furthermore, since $\Gamma \neq \emptyset$, choose $(p, q) \in \Gamma$. Then by Step 3 of the algorithm, $f_{n} \in C$ and $g_{n} \in D$ for each $n \geq 0$, and hence by Lemma 2.14, $\left\langle p-f_{n}, T f_{n}\right\rangle \leq 0$ and $\left\langle q-g_{n}, S g_{n}\right\rangle \leq 0$ for each $n \geq 0$. Hence, $p \in C_{n}$ and $q \in D_{n}$ for each $n \geq 0$, showing that $C_{n} \neq \emptyset$ and $D_{n} \neq \emptyset$ for each $n \geq 0$.

Lemma 3.2. Assume that Conditions (A1) - (A5) and (B1) - (B4) are satisfied. If $\left(u_{n}\right),\left(z_{n}\right),\left(v_{n}\right)$ and $\left(w_{n}\right)$ are sequences generated by Algorithm 3.1, then $\xi \lambda^{-1}\left\|r_{2}\left(u_{n}, z_{n}\right)\right\|^{2} \leq\left\langle r_{2}\left(u_{n}, z_{n}\right), T u_{n}\right\rangle$ and $\xi \lambda^{-1}\left\|s_{2}\left(v_{n}, w_{n}\right)\right\|^{2} \leq\left\langle s_{2}\left(v_{n}, w_{n}\right), S v_{n}\right\rangle$.

Proof. Using Lemma 2.3 and the definition of $z_{n}$, we have

$$
\left\langle z-z_{n}, J_{E_{1}} u_{n}-\lambda T u_{n}-J_{E_{1}} z_{n}\right\rangle \leq 0, \forall z \in C .
$$

In particular, for $z=u_{n} \in C$, we obtain $\left\langle u_{n}-z_{n}, J_{E_{1}} u_{n}-J_{E_{1}} z_{n}\right\rangle \leq \lambda\left\langle u_{n}-z_{n}, T u_{n}\right\rangle$. Using Lemma 2.8, we obtain

$$
\xi\left\|r_{2}\left(u_{n}, z_{n}\right)\right\|^{2} \leq \xi_{1}\left\|u_{n}-z_{n}\right\|^{2} \leq \lambda\left\langle u_{n}-z_{n}, T u_{n}\right\rangle .
$$

The second inequality of the lemma can be proved in a similar way. 
Lemma 3.3. Assume that Conditions (A1) - (A5) and (B1) - (B4) are met.

Let $(p, q) \in \Gamma, F_{n}(x)=\left\langle x-f_{n}, T f_{n}\right\rangle$ and $G_{n}(y)=\left\langle y-g_{n}, S g_{n}\right\rangle$. Then

(i) $F_{n}(p) \leq 0$ and $F_{n}\left(u_{n}\right) \geq \tau_{n}\left(\xi \lambda^{-1}-\mu\right)\left\|r_{2}\left(u_{n}, z_{n}\right)\right\|^{2}$, and

(ii) $G_{n}(q) \leq 0$ and $G_{n}\left(v_{n}\right) \geq \kappa_{n}\left(\xi \lambda^{-1}-\mu\right)\left\|s_{2}\left(v_{n}, w_{n}\right)\right\|^{2}$.

In particular, if $r_{2}\left(u_{n}, z_{n}\right) \neq 0$ and $s_{2}\left(v_{n}, w_{n}\right) \neq 0$, then $F_{n}\left(u_{n}\right)>0$ and $G_{n}\left(v_{n}\right)>0$, respectively.

Proof. (i) Since $(p, q) \in \Gamma$, it follows that $p \in \operatorname{VI}(C, T)$ and $q \in \mathrm{VI}(D, S)$.

By Lemma 2.14, $F_{n}(p)=\left\langle p-f_{n}, T f_{n}\right\rangle \leq 0$ for each $n \geq 0$.

Next, we observe from Step 3 of the algorithm and the definition of $F_{n}$ that

$$
F_{n}\left(u_{n}\right)=\left\langle u_{n}-f_{n}, T f_{n}\right\rangle=\left\langle\tau_{n} r_{2}\left(u_{n}, z_{n}\right), T f_{n}\right\rangle=\tau_{n}\left\langle r_{2}\left(u_{n}, z_{n}\right), T f_{n}\right\rangle .
$$

But from the search rule $(3.1),\left\langle r_{2}\left(u_{n}, z_{n}\right), T u_{n}-T f_{n}\right\rangle \leq \mu\left\|r_{2}\left(u_{n}, z_{n}\right)\right\|^{2}$, which together with Lemma 3.2 imply that

$$
\begin{aligned}
F_{n}\left(u_{n}\right)=\tau_{n}\left\langle r_{2}\left(u_{n}, z_{n}\right), T f_{n}\right\rangle & \geq \tau_{n}\left[\left\langle r_{2}\left(u_{n}, z_{n}\right), T u_{n}\right\rangle-\mu\left\|r_{2}\left(u_{n}, z_{n}\right)\right\|^{2}\right] \\
& \geq \tau_{n}\left[\xi \lambda^{-1}\left\|r_{2}\left(u_{n}, z_{n}\right)\right\|^{2}-\mu\left\|r_{2}\left(u_{n}, z_{n}\right)\right\|^{2}\right] .
\end{aligned}
$$

Obviously, if $r_{2}\left(u_{n}, z_{n}\right) \neq 0$, then from Condition (B2), we have $F_{n}\left(u_{n}\right)>0$.

(ii) The proof is similar to the proof of part (i) above.

Lemma 3.4. Assume that Conditions (A1) - (A5) and (B1) - (B4) hold.

(a). If there exist $\left(u_{n_{k}}\right) \subset\left(u_{n}\right)$ and $\left(z_{n_{k}}\right) \subset\left(z_{n}\right)$ such that $\left(u_{n_{k}}\right)$ converges weakly to $x \in E_{1}$ and $\tau_{n_{k}}\left\|u_{n_{k}}-z_{n_{k}}\right\|^{2} \rightarrow 0$ as $k \rightarrow \infty$, then $x \in V I(C, T)$.

(b). If there exist $\left(v_{n_{i}}\right) \subset\left(v_{n}\right)$ and $\left(w_{n_{i}}\right) \subset\left(w_{n}\right)$ such that $\left(v_{n_{i}}\right)$ converges weakly to $y \in E_{2}$ and $\kappa_{n_{i}}\left\|v_{n_{i}}-w_{n_{i}}\right\|^{2} \rightarrow 0$ as $i \rightarrow \infty$, then $y \in V I(D, S)$.

Proof. (a). By considering two possible cases on $\tau_{n_{k}}$, we first show that

$$
\lim _{k \rightarrow \infty}\left\|u_{n_{k}}-z_{n_{k}}\right\|=0
$$

Case I: Assume that $\liminf _{k \rightarrow \infty} \tau_{n_{k}}>0$.

Then there exists a constant $\tau>0$ such that $\tau_{n_{k}} \geq \tau>0$ for all $k \in \mathbb{N}$. Then

$$
\left\|u_{n_{k}}-z_{n_{k}}\right\|^{2}=\tau_{n_{k}}^{-1}\left[\tau_{n_{k}}\left\|u_{n_{k}}-z_{n_{k}}\right\|^{2}\right] \leq \tau^{-1}\left[\tau_{n_{k}}\left\|u_{n_{k}}-z_{n_{k}}\right\|^{2}\right]
$$

Therefore, (3.5) follows from (3.6) and the assumption in the lemma.

Case II: Assume that $\liminf _{k \rightarrow \infty} \tau_{n_{k}}=0$.

In this case, we take a subsequence $\left(n_{k_{j}}\right)$ of $\left(n_{k}\right)$ if necessary, we assume without loss of generality that

$$
\lim _{k \rightarrow \infty} \tau_{n_{k}}=0 \quad \text { and } \quad \lim _{k \rightarrow \infty}\left\|u_{n_{k}}-z_{n_{k}}\right\|=a>0 .
$$

Let $f_{k}=\frac{1}{l} \tau_{n_{k}} z_{n_{k}}+\left(1-\frac{1}{l} \tau_{n_{k}}\right) u_{n_{k}}$. Using (3.7), we get

$$
\lim _{k \rightarrow \infty}\left\|f_{k}-u_{n_{k}}\right\|=\lim _{k \rightarrow \infty} l^{-1} \tau_{n_{k}}\left\|u_{n_{k}}-z_{n_{k}}\right\|=0 .
$$

Since $T$ is uniformly continuous on bounded subsets of $C$, it follows from (3.8) that $\left\|T f_{k}-T u_{n_{k}}\right\| \rightarrow 0$ as $k \rightarrow \infty$. 
From (3.1), we have $\left\langle T u_{n_{k}}-T f_{k}, u_{n_{k}}-z_{n_{k}}\right\rangle>\mu\left\|u_{n_{k}}-z_{n_{k}}\right\|^{2}$, and it follows that $\left\|u_{n_{k}}-z_{n_{k}}\right\| \rightarrow 0$ as $k \rightarrow \infty$. This contradicts (3.7), hence the limit in (3.5) must hold. Finally, we show that $x \in \operatorname{VI}(C, T)$.

Since $C$ is weakly closed, we have $x \in C$. Furthermore, from the fact that $J_{E_{1}}$ is uniformly continuous on bounded subsets of $E_{1}$, we have

$$
\lim _{k \rightarrow \infty}\left\|J_{E_{1}} u_{n_{k}}-J_{E_{1}} z_{n_{k}}\right\|=0 \text {. }
$$

From Lemma 2.3 and $z_{n} \in C$, we get $\left\langle z-z_{n_{k}}, J_{E_{1}} u_{n_{k}}-\lambda T u_{n_{k}}-J_{E_{1}} z_{n_{k}}\right\rangle \leq 0$ for all $z \in C$, which implies that

$$
\left\langle z-z_{n_{k}}, J_{E_{1}} u_{n_{k}}-J_{E_{1}} z_{n_{k}}\right\rangle-\lambda\left\langle u_{n_{k}}-z_{n_{k}}, T u_{n_{k}}\right\rangle \leq \lambda\left\langle z-u_{n_{k}}, T u_{n_{k}}\right\rangle .
$$

Taking the limit inferior as $k \rightarrow \infty$ and using (3.9), we get

$$
\liminf _{k \rightarrow \infty}\left\langle z-u_{n_{k}}, T u_{n_{k}}\right\rangle \geq 0 \quad \forall z \in C .
$$

Thus the inequality in (3.11) implies that we can choose a decreasing sequence of positive real numbers $\left(\delta_{k}\right)$ such that $\left(\delta_{k}\right)$ converges to zero as $k \rightarrow \infty$, and for each $\delta_{k}$ there exists $N_{k}$, the smallest positive integer, such that

$$
\left\langle z-u_{n_{j}}, T u_{n_{j}}\right\rangle+\delta_{k} \geq 0 \quad \forall j \geq N_{k} \quad \text { and } \quad \forall z \in C .
$$

Since $\left(\delta_{k}\right)$ is decreasing, the sequence $\left(N_{k}\right)$ is increasing.

Note that if there exists $N>0$ such that $T u_{N_{k}}=0$ for all $k \geq N$, then it can be shown easily that $x \in \mathrm{VI}(C, T)$.

On the other hand, if there exists a subsequence $\left(N_{k_{i}}\right)$ of $\left(N_{k}\right)$, again denoted by $\left(N_{k}\right)$, such that $T u_{N_{k}} \neq 0$ for all $k \in \mathbb{N}$, then $\left\langle a_{N_{k}}, T u_{N_{k}}\right\rangle=1$ for each $k \in \mathbb{N}$, where

$$
a_{N_{k}}=\frac{J_{E_{1}}^{-1} T u_{N_{k}}}{\left\|T u_{N_{k}}\right\|^{2}} \text {. }
$$

From (3.12), we deduce that $\left\langle z+\delta_{k} a_{N_{k}}-u_{N_{k}}, T u_{N_{k}}\right\rangle \geq 0$ for each $k \in \mathbb{N}$ and $z \in C$. Since $T$ is pseudomonotone, it follows that

$$
\left\langle z+\delta_{k} a_{N_{k}}-u_{N_{k}}, T\left(z+\delta_{k} a_{N_{k}}\right)\right\rangle \geq 0 \quad \forall k \in \mathbb{N} \quad \text { and } \quad \forall z \in C .
$$

But by our assumption, $\left(u_{N_{k}}\right)$ converges weakly to $x \in C$. Also $T$ is sequentially weakly continuous on $E_{1}$ implies that $\left(T u_{N_{k}}\right)$ converges weakly to $T x$. Moreover, we can suppose that $T x \neq 0$ (otherwise, $x$ is in $\mathrm{VI}(C, T)$ ) and so

$$
0 \leq\|T x\| \leq \liminf _{k \rightarrow \infty}\left\|T u_{N_{k}}\right\| .
$$

Since $\left(u_{N_{k}}\right) \subset\left(u_{n_{k}}\right)$ and $\left(\delta_{k}\right)$ converges to zero as $k \rightarrow \infty$, we obtain that

$$
0 \leq \limsup _{k \rightarrow \infty}\left\|\delta_{k} a_{N_{k}}\right\|=\limsup _{k \rightarrow \infty}\left(\frac{\delta_{k}}{\left\|T u_{N_{k}}\right\|}\right) \leq \frac{\limsup _{k \rightarrow \infty} \delta_{k}}{\liminf _{k \rightarrow \infty}\left\|T u_{N_{k}}\right\|} \leq \frac{0}{\|T x\|},
$$

and hence $\left\|\delta_{k} a_{N_{k}}\right\| \rightarrow 0$ as $k \rightarrow \infty$. Therefore, taking the limit in (3.13) as $k \rightarrow \infty$, we get $\langle z-x, T z\rangle \geq 0$ for all $z \in C$. In view of Lemma 2.14, we conclude that $x \in \mathrm{VI}(C, T)$.

Part (b) of the Lemma can be proved in a similar way. 
Remark 3.5. If in Lemma 3.4, $T: E_{1} \rightarrow E_{1}^{*}$ and $S: E_{2} \rightarrow E_{2}^{*}$ are uniformly continuous and monotone mappings, then for all $z \in C$, we have from (3.10)

$$
\begin{aligned}
\left\langle z-z_{n_{k}}, J_{E_{1}} u_{n_{k}}-J_{E_{1}} z_{n_{k}}\right\rangle & +\lambda\left\langle z_{n_{k}}-u_{n_{k}}, T u_{n_{k}}\right\rangle \leq \lambda\left\langle z-u_{n_{k}}, T u_{n_{k}}-T z\right\rangle \\
& +\lambda\left\langle z-u_{n_{k}}, T z\right\rangle \leq \lambda\left\langle z-u_{n_{k}}, T z\right\rangle .
\end{aligned}
$$

Taking the limit as $k \rightarrow \infty$, we get $0 \leq\langle z-x, T z\rangle$. It then follows from Lemma 2.14 that $x \in \mathrm{VI}(C, T)$. Similarly, we get $y \in \mathrm{VI}(D, S)$.

Lemma 3.6. Let $\left(x_{n}\right)$ and $\left(y_{n}\right)$ be sequences generated by Algorithm 3.1. Assume that the Conditions (A1) - (A5) and (B1) - (B4) hold. Then $\left(x_{n}\right)$ and $\left(y_{n}\right)$ are bounded. Hence, $\left(u_{n}\right),\left(v_{n}\right),\left(z_{n}\right)$ and $\left(w_{n}\right)$ are bounded sequences.

Proof. Let $(p, q) \in \Gamma$. Then $p \in \operatorname{VI}(C, T), q \in \mathrm{VI}(D, S)$ and $A p=B q$.

Denote $q_{n}=J_{E_{1}}^{-1}\left[J_{E_{1}} x_{n}-\gamma_{n} A^{*} J_{E_{3}}\left(A x_{n}-B y_{n}\right)\right]$. Then $u_{n}=\Pi_{C} q_{n}$ and so from Lemmas 2.1 and 2.4 , and the properties of the mapping $V$, we obtain

$$
\begin{aligned}
\phi\left(p, u_{n}\right) & \leq \phi\left(p, J_{E_{1}}^{-1}\left[J_{E_{1}} x_{n}-\gamma_{n} A^{*} J_{E_{3}}\left(A x_{n}-B y_{n}\right)\right]\right) \\
& =V\left(p, J_{E_{1}} x_{n}-\gamma_{n} A^{*} J_{E_{3}}\left(A x_{n}-B y_{n}\right)\right) \\
& \leq V\left(p, J_{E_{1}} x_{n}\right)-2\left\langle q_{n}-p, \gamma_{n} A^{*} J_{E_{3}}\left(A x_{n}-B y_{n}\right)\right\rangle \\
& =\phi\left(p, x_{n}\right)-2 \gamma_{n}\left\langle q_{n}-p, A^{*} J_{E_{3}}\left(A x_{n}-B y_{n}\right)\right\rangle \\
& =\phi\left(p, x_{n}\right)-2 \gamma_{n}\left\langle A q_{n}-A p, J_{E_{3}}\left(A x_{n}-B y_{n}\right)\right\rangle .
\end{aligned}
$$

Furthermore, from Lemma 2.5, Lemma 2.1 and (3.14), we have

$$
\begin{aligned}
\phi\left(p, x_{n+1}\right) & \leq \alpha_{n} \phi(p, u)+\left(1-\alpha_{n}\right) \phi\left(p, \Pi_{C_{n}} u_{n}\right) \\
& \leq \alpha_{n} \phi(p, u)+\left(1-\alpha_{n}\right) \phi\left(p, u_{n}\right) \\
& \leq \alpha_{n} \phi(p, u)+\left(1-\alpha_{n}\right)\left[\phi\left(p, x_{n}\right)\right. \\
& \left.-2 \gamma_{n}\left\langle A q_{n}-A p, J_{E_{3}}\left(A x_{n}-B y_{n}\right)\right\rangle\right] .
\end{aligned}
$$

Similarly, if we denote $t_{n}=J_{E_{2}}^{-1}\left[J_{E_{2}} y_{n}+\gamma_{n} B^{*} J_{E_{3}}\left(A x_{n}-B y_{n}\right)\right]$, then

$$
\phi\left(q, v_{n}\right) \leq \phi\left(q, y_{n}\right)+2 \gamma_{n}\left\langle B t_{n}-B q, J_{E_{3}}\left(A x_{n}-B y_{n}\right)\right\rangle,
$$

and therefore, from Lemma 2.5, Lemma 2.1 and (3.17)

$$
\begin{aligned}
\phi\left(q, y_{n+1}\right) & \leq \alpha_{n} \phi(q, v)+\left(1-\alpha_{n}\right) \phi\left(q, \Pi_{D_{n}} v_{n}\right) \\
& \leq\left(1-\alpha_{n}\right)\left[\phi\left(q, y_{n}\right)+2 \gamma_{n}\left\langle B t_{n}-B q, J_{E_{3}}\left(A x_{n}-B y_{n}\right)\right\rangle\right] \\
& +\alpha_{n} \phi(q, v) .
\end{aligned}
$$

Denote $\Upsilon=\phi(p, u)+\phi(q, v)$ and $\Theta_{n}=\phi\left(p, x_{n}\right)+\phi\left(q, y_{n}\right)$. Then adding (3.16) and (3.19), we get

$$
\Theta_{n+1} \leq\left(1-\alpha_{n}\right)\left[\Theta_{n}-2 \gamma_{n}\left\langle A q_{n}-B t_{n}, J_{E_{3}}\left(A x_{n}-B y_{n}\right)\right\rangle\right]+\alpha_{n} \Upsilon .
$$

Now observe that

$$
\begin{aligned}
& -\left\langle A q_{n}-B t_{n}, J_{E_{3}}\left(A x_{n}-B y_{n}\right)\right\rangle=-\left\langle A x_{n}-B y_{n}, J_{E_{3}}\left(A x_{n}-B y_{n}\right)\right\rangle \\
& -\left\langle A q_{n}-A x_{n}, J_{E_{3}}\left(A x_{n}-B y_{n}\right)\right\rangle-\left\langle B y_{n}-B t_{n}, J_{E_{3}}\left(A x_{n}-B y_{n}\right)\right\rangle \\
\leq & \left\|q_{n}-x_{n}\right\|\left\|A^{*} J_{E_{3}}\left(A x_{n}-B y_{n}\right)\right\|-\left\|A x_{n}-B y_{n}\right\|^{2} \\
+ & \left\|y_{n}-t_{n}\right\|\left\|B^{*} J_{E_{3}}\left(A x_{n}-B y_{n}\right)\right\| .
\end{aligned}
$$


From Lemma 2.8 and the definition of $q_{n}$, we obtain

$$
\left\|q_{n}-x_{n}\right\| \leq \frac{1}{\xi_{1}}\left\|\gamma_{n} A^{*} J_{E_{3}}\left(A x_{n}-B y_{n}\right)\right\| \leq \frac{\gamma_{n}}{\xi}\left\|A^{*} J_{E_{3}}\left(A x_{n}-B y_{n}\right)\right\| .
$$

Similarly, from Lemma 2.8 and the definition of $t_{n}$, we obtain

$$
\left\|y_{n}-t_{n}\right\| \leq \gamma_{n} \xi^{-1}\left\|B^{*} J_{E_{3}}\left(A x_{n}-B y_{n}\right)\right\|
$$

Combining (3.21), (3.22) and (3.23), we obtain

$$
\begin{aligned}
& -2 \gamma_{n}\left\langle A q_{n}-B t_{n}, J_{E_{3}}\left(A x_{n}-B y_{n}\right)\right\rangle \leq-2 \gamma_{n}\left\|A x_{n}-B y_{n}\right\|^{2} \\
& +\quad 2 \gamma_{n}^{2} \xi^{-1}\left[\left\|A^{*} J_{E_{3}}\left(A x_{n}-B y_{n}\right)\right\|^{2}+\left\|B^{*} J_{E_{3}}\left(A x_{n}-B y_{n}\right)\right\|^{2}\right] \\
& \leq-\gamma\left\|A x_{n}-B y_{n}\right\|^{2}
\end{aligned}
$$

for all $n \in \Omega$, where the last inequality follows from Assumption (B4). If $n \notin \Omega$, then $A x_{n}-B y_{n}=0$, and in this case inequality (3.24) follows trivially. Finally, using (3.24) in (3.20), we obtain $\Theta_{n+1} \leq\left(1-\alpha_{n}\right) \Theta_{n}+\alpha_{n} \Upsilon$. By mathematical induction, $\Theta_{n} \leq \max \left\{\Theta_{0}, \Upsilon\right\}$ for all $n \geq 0$, showing that the sequence $\left(\phi\left(p, x_{n}\right)+\phi\left(q, y_{n}\right)\right)$ is bounded, which implies that $\left(\phi\left(p, x_{n}\right)\right)$ and $\left(\phi\left(q, y_{n}\right)\right)$ are bounded. By the properties of $\phi$, we conclude that $\left(x_{n}\right)$ and $\left(y_{n}\right)$ are bounded. Consequently, $\left(u_{n}\right),\left(v_{n}\right),\left(z_{n}\right)$ and $\left(w_{n}\right)$ are bounded.

Theorem 3.7. Suppose the Assumptions (A1) - (A5) and (B1) - (B4) hold. Then the sequence $\left(\left(x_{n}, y_{n}\right)\right)$ generated by Algorithm 3.1 converges strongly to $\left(x^{*}, y^{*}\right) \in \Gamma$, where $\left(x^{*}, y^{*}\right)=\prod_{\Gamma}(u, v)$.

Proof. Let $\left(x^{*}, y^{*}\right) \in \Gamma$ be such that $\left(x^{*}, y^{*}\right)=\prod_{\Gamma}(u, v)$. Denote

$$
\Lambda_{n}=2\left\langle\left(x_{n}, y_{n}\right)-\left(x^{*}, y^{*}\right),\left(J_{E_{1}} u, J_{E_{2}} v\right)-\left(J_{E_{1}} x^{*}, J_{E_{2}} y^{*}\right)\right\rangle \text {. }
$$

Then for some $M_{1}>0$, we have

$$
\begin{aligned}
\Lambda_{n+1} & =2\left[\left\langle x_{n}-x^{*}, J_{E_{1}} u-J_{E_{1}} x^{*}\right\rangle+\left\langle y_{n}-y^{*}, J_{E_{2}} v-J_{E_{2}} y^{*}\right\rangle\right] \\
& +2\left[\left\langle x_{n+1}-x_{n}, J_{E_{1}} u-J_{E_{1}} x^{*}\right\rangle+\left\langle y_{n+1}-y_{n}, J_{E_{2}} v-J_{E_{2}} y^{*}\right\rangle\right] \\
& \leq \Lambda_{n}+M_{1}\left[\left\|x_{n+1}-x_{n}\right\|+\left\|y_{n+1}-y_{n}\right\|\right] .
\end{aligned}
$$

Since the sequences $\left(u_{n}\right)$ and $\left(z_{n}\right)$ are bounded by Lemma 3.6, the sequence $\left(f_{n}\right)$ is bounded. But $T$ is uniformly continuous implies that there exists $L>0$ such that $\left\|T f_{n}\right\| \leq L$ for all $n \geq 0$. We can then deduce that for each $n \geq 0$, the mapping $F_{n}$ is Lipschitz continuous with Lipschitz constant $L>0$.

Now, from Lemma 2.1,

$$
\phi\left(x^{*}, \Pi_{C_{n}} u_{n}\right) \leq \phi\left(x^{*}, u_{n}\right)-\phi\left(\Pi_{C_{n}} u_{n}, u_{n}\right) .
$$

Using Lemmas 2.10 and 3.3, we obtain

$$
\phi\left(\Pi_{C_{n}} u_{n}, u_{n}\right) \geq L_{1} \tau_{n}^{2}\left\|r_{2}\left(u_{n}, z_{n}\right)\right\|^{4}
$$

for some $L_{1}>0$. Combining (3.26), (3.27) and (3.14), we get

$$
\begin{aligned}
\phi\left(x^{*}, \Pi_{C_{n}} u_{n}\right) & \leq \phi\left(x^{*}, x_{n}\right)-2 \gamma_{n}\left\langle A q_{n}-A x^{*}, J_{E_{3}}\left(A x_{n}-B y_{n}\right)\right\rangle \\
& -L_{1} \tau_{n}^{2}\left\|u_{n}-z_{n}\right\|^{4} .
\end{aligned}
$$


From the definition of $x_{n}$, the properties of the map $V$ and Lemma 2.4,

$$
\begin{aligned}
\phi\left(x^{*}, x_{n+1}\right) & =V\left(x^{*}, \alpha_{n} J_{E_{1}} u+\left(1-\alpha_{n}\right) J_{E_{1}} \Pi_{C_{n}} u_{n}\right) \\
& \leq V\left(x^{*}, \alpha_{n} J_{E_{1}} x^{*}+\left(1-\alpha_{n}\right) J_{E_{1}} \Pi_{C_{n}} u_{n}\right) \\
& +2 \alpha_{n}\left\langle x_{n+1}-x^{*}, J_{E_{1}} u-J_{E_{1}} x^{*}\right\rangle \\
& =\phi\left(x^{*}, J_{E_{1}}^{-1}\left[\alpha_{n} J_{E_{1}} x^{*}+\left(1-\alpha_{n}\right) J_{E_{1}} \Pi_{C_{n}} u_{n}\right]\right) \\
& +2 \alpha_{n}\left\langle x_{n+1}-x^{*}, J_{E_{1}} u-J_{E_{1}} x^{*}\right\rangle .
\end{aligned}
$$

Using Lemma 2.5, (3.29) and (3.28), we obtain for some $\widehat{K}_{1}>0$,

$$
\begin{aligned}
\phi\left(x^{*}, x_{n+1}\right) & \leq\left(1-\alpha_{n}\right) \phi\left(x^{*}, \Pi_{C_{n}} u_{n}\right)+2 \alpha_{n}\left\langle x_{n+1}-x^{*}, J_{E_{1}} u-J_{E_{1}} x^{*}\right\rangle \\
& \leq\left(1-\alpha_{n}\right)\left[\phi\left(x^{*}, x_{n}\right)-2 \gamma_{n}\left\langle A q_{n}-A x^{*}, J_{E_{3}}\left(A x_{n}-B y_{n}\right)\right\rangle\right] \\
& +2 \alpha_{n}\left\langle x_{n+1}-x^{*}, J_{E_{1}} u-J_{E_{1}} x^{*}\right\rangle-\widehat{K}_{1} \tau_{n}^{2}\left\|u_{n}-z_{n}\right\|^{4} .
\end{aligned}
$$

Similarly, we deduce that for each $n \geq 0$,

$$
\phi\left(y^{*}, \Pi_{D_{n}} v_{n}\right) \leq \phi\left(y^{*}, v_{n}\right)-\phi\left(\Pi_{D_{n}} v_{n}, v_{n}\right),
$$

and also, for some $\widehat{K}_{2}>0$, we derive

$$
\begin{aligned}
\phi\left(y^{*}, y_{n+1}\right) & \leq\left(1-\alpha_{n}\right)\left[\phi\left(y^{*}, y_{n}\right)+2 \gamma_{n}\left\langle B t_{n}-B y^{*}, J_{E_{3}}\left(A x_{n}-B y_{n}\right)\right\rangle\right] \\
& +2 \alpha_{n}\left\langle y_{n+1}-y^{*}, J_{E_{2}} v-J_{E_{2}} y^{*}\right\rangle-\widehat{K}_{2} \kappa_{n}^{2}\left\|v_{n}-w_{n}\right\|^{4} .
\end{aligned}
$$

Denote $\Theta_{n}^{*}=\phi\left(x^{*}, x_{n}\right)+\phi\left(y^{*}, y_{n}\right)$ and $\Upsilon^{*}=\phi\left(x^{*}, u\right)+\phi\left(y^{*}, v\right)$. Then combining (3.30), (3.32) and (3.24), we get

$$
\Theta_{n+1}^{*} \leq\left(1-\alpha_{n}\right) \Theta_{n}^{*}+\alpha_{n} \Lambda_{n+1}-L^{*}\left[\tau_{n}^{2}\left\|u_{n}-z_{n}\right\|^{4}+\kappa_{n}^{2}\left\|v_{n}-w_{n}\right\|^{4}\right]
$$

for some $L^{*}>0$. Furthermore, from (3.15), (3.26) and (3.14), we obtain

$$
\begin{aligned}
\phi\left(x^{*}, x_{n+1}\right) & \leq \alpha_{n} \phi\left(x^{*}, u\right)+\left(1-\alpha_{n}\right)\left[\phi\left(x^{*}, x_{n}\right)-\phi\left(\Pi_{C_{n}} u_{n}, u_{n}\right)\right] \\
& -2\left(1-\alpha_{n}\right) \gamma_{n}\left\langle A q_{n}-A x^{*}, J_{E_{3}}\left(A x_{n}-B y_{n}\right)\right\rangle .
\end{aligned}
$$

Similarly, from (3.18), (3.31) and (3.17), we obtain

$$
\begin{aligned}
\phi\left(y^{*}, y_{n+1}\right) & \leq \alpha_{n} \phi\left(y^{*}, v\right)+\left(1-\alpha_{n}\right)\left[\phi\left(y^{*}, y_{n}\right)-\phi\left(\Pi_{D_{n}} v_{n}, v_{n}\right)\right] \\
& +2\left(1-\alpha_{n}\right) \gamma_{n}\left\langle B t_{n}-B y^{*}, J_{E_{3}}\left(A x_{n}-B y_{n}\right)\right\rangle .
\end{aligned}
$$

Adding (3.34) and (3.35), and using (3.24), we obtain for some $M>0$

$$
\Theta_{n+1}^{*} \leq \Theta_{n}^{*}+\alpha_{n} M-\gamma\left\|A x_{n}-B y_{n}\right\|^{2}-\left[\phi\left(\Pi_{C_{n}} u_{n}, u_{n}\right)+\phi\left(\Pi_{D_{n}} v_{n}, v_{n}\right)\right],
$$

which implies that

$$
\begin{aligned}
\phi\left(\Pi_{C_{n}} u_{n}, u_{n}\right)+\phi\left(\Pi_{D_{n}} v_{n}, v_{n}\right)+\gamma\left\|A x_{n}-B y_{n}\right\|^{2} & \leq \Theta_{n}^{*}-\Theta_{n+1}^{*} \\
& +\alpha_{n} M .
\end{aligned}
$$

Finally, we show that the sequence $\left(\Theta_{n}^{*}\right)$ converges strongly to zero as $n \rightarrow \infty$. For this, we consider two possible cases on $\left(\Theta_{n}^{*}\right)$. 
Case I. Assume that there exists $n_{0} \in \mathbb{N}$ such that the sequence of real numbers $\left(\Theta_{n}^{*}\right)$ is decreasing for all $n \geq n_{0}$. It then follows that $\left(\Theta_{n}^{*}\right)$ is convergent. Taking the limit in (3.36) as $n \rightarrow \infty$, we get

$$
\lim _{n \rightarrow \infty}\left\|A x_{n}-B y_{n}\right\|=0 .
$$

From the definition of $q_{n}$, Lemma 2.1, Lemma 2.4 and (3.22), we have

$$
\begin{aligned}
\phi\left(x_{n}, u_{n}\right) & \leq \phi\left(x_{n}, J_{E_{1}}^{-1}\left[J_{E_{1}} x_{n}-\gamma_{n} A^{*} J_{E_{3}}\left(A x_{n}-B y_{n}\right)\right]\right) \\
& =V\left(x_{n}, J_{E_{1}} x_{n}-\gamma_{n} A^{*} J_{E_{3}}\left(A x_{n}-B y_{n}\right)\right) \\
& \leq V\left(x_{n}, J_{E_{1}} x_{n}\right)-2\left\langle q_{n}-x_{n}, \gamma_{n} A^{*} J_{E_{3}}\left(A x_{n}-B y_{n}\right)\right\rangle \\
& \leq \phi\left(x_{n}, x_{n}\right)+2 \gamma_{n}^{2} \xi^{-1}\|A\|^{2}\left\|A x_{n}-B y_{n}\right\|^{2} .
\end{aligned}
$$

Taking the limit as $n \rightarrow \infty$ and noticing (3.37), yield $\phi\left(x_{n}, u_{n}\right) \rightarrow 0$ as $n \rightarrow \infty$. Using Lemma 2.2, we obtain

$$
\lim _{n \rightarrow \infty}\left\|x_{n}-u_{n}\right\|=0
$$

Similarly, starting with the definition of $t_{n}$, we obtain

$$
\lim _{n \rightarrow \infty}\left\|y_{n}-v_{n}\right\|=0
$$

Moreover, we also obtain from (3.36) and Lemma 2.2

$$
\lim _{n \rightarrow \infty}\left\|\Pi_{C_{n}} u_{n}-u_{n}\right\|=0 \text { and } \lim _{n \rightarrow \infty}\left\|\Pi_{D_{n}} v_{n}-v_{n}\right\|=0 .
$$

From the definition of $x_{n}$ and Lemma 2.8,

$$
\begin{aligned}
\left\|x_{n+1}-u_{n}\right\| & \leq \xi_{1}^{-1}\left\|\alpha_{n} J_{E_{1}} u+\left(1-\alpha_{n}\right) J_{E_{1}} \Pi_{C_{n}} u_{n}-J_{E_{1}} u_{n}\right\| \\
& \leq \alpha_{n} K_{1}+\xi_{1}^{-1}\left\|J_{E_{1}} \Pi_{C_{n}} u_{n}-J_{E_{1}} u_{n}\right\|,
\end{aligned}
$$

for some constant $K_{1}>0$. Since $J_{E_{1}}$ is norm to norm uniformly continuous on bounded subsets of $E_{1}$, we conclude from (3.40) and (3.41) that

$$
\lim _{n \rightarrow \infty}\left\|x_{n+1}-u_{n}\right\|=0 \text {. }
$$

Therefore, combining (3.38) and (3.42) yield

$$
\lim _{n \rightarrow \infty}\left\|x_{n+1}-x_{n}\right\|=0 \text {. }
$$

Similarly, one can show that

$$
\lim _{n \rightarrow \infty}\left\|y_{n+1}-y_{n}\right\|=0
$$

Since $\left(x_{n}\right)$ and $\left(y_{n}\right)$ are bounded by Lemma 3.6, we obtain from (3.33)

$$
L^{*}\left[\tau_{n}^{2}\left\|u_{n}-z_{n}\right\|^{4}+\kappa_{n}^{2}\left\|v_{n}-w_{n}\right\|^{4}\right] \leq \Theta_{n}^{*}-\Theta_{n+1}^{*}+\alpha_{n} \Lambda_{n+1},
$$

But the convergence of $\left(\Theta_{n}^{*}\right)$ and Assumption (B3) imply that

$$
\lim _{n \rightarrow \infty} \tau_{n}\left\|u_{n}-z_{n}\right\|^{2}=0 \text { and } \lim _{n \rightarrow \infty} \kappa_{n}\left\|v_{n}-w_{n}\right\|^{2}=0 .
$$


Now, we deduce from Lemma 3.6 that $\left(\left(x_{n}, y_{n}\right)\right)$ is a bounded sequence in $C \times D$. Therefore, there exists a subsequence $\left(\left(x_{n_{k}}, y_{n_{k}}\right)\right)$ of $\left(\left(x_{n}, y_{n}\right)\right)$ such that $\left(\left(x_{n_{k}}, y_{n_{k}}\right)\right)$ converges weakly to $(x, y)$ in $E_{1} \times E_{2}$ and

$$
\limsup _{n \rightarrow \infty} \Lambda_{n}=\lim _{k \rightarrow \infty} \Lambda_{n_{k}}
$$

It then follows that $\left(x_{n_{k}}\right)$ converges weakly to $x$ in $E_{1}$ and $\left(y_{n_{k}}\right)$ converges weakly to $y$ in $E_{2}$. From (3.38), $\left(u_{n_{k}}\right)$ converges weakly to $x$ in $E_{1}$ and from $(3.39),\left(v_{n_{k}}\right)$ converges weakly to $y$ in $E_{2}$. Using (3.46) and Lemma 3.4, we conclude that $x \in \operatorname{VI}(C, T)$ and $y \in \mathrm{VI}(D, S)$, respectively. Moreover,

$$
\|A x-B y\|^{2} \leq 2\left\langle A x-A x_{n_{k}}+B y_{n_{k}}-B y, J_{E_{3}}(A x-B y)\right\rangle+\left\|A x_{n_{k}}-B y_{n_{k}}\right\|^{2} .
$$

Since $\left(x_{n_{k}}\right)$ converges weakly to $x$, it follows that $\left(A x_{n_{k}}\right)$ converges weakly to $A x$. Similarly, $\left(y_{n_{k}}\right)$ converges weakly to $y$ implies that $\left(B y_{n_{k}}\right)$ converges weakly to $B y$. Using (3.37), we get $A x=B y$. Consequently, $(x, y) \in \Gamma$.

From (3.25), (3.47), (3.43), (3.44) and Lemma 2.3, we obtain

$$
\begin{aligned}
\limsup _{n \rightarrow \infty} \Lambda_{n+1} & \leq \limsup _{n \rightarrow \infty} \Lambda_{n}+M_{1} \limsup _{n \rightarrow \infty}\left[\left\|x_{n+1}-x_{n}\right\|+\left\|y_{n+1}-y_{n}\right\|\right] \\
& =\lim _{k \rightarrow \infty} \Lambda_{n_{k}}+M_{1} \lim _{k \rightarrow \infty}\left[\left\|x_{n_{k}+1}-x_{n_{k}}\right\|+\left\|y_{n_{k}+1}-y_{n_{k}}\right\|\right] \\
& =2\left\langle(x, y)-\left(x^{*}, y^{*}\right),\left(J_{E_{1}} u, J_{E_{2}} v\right)-\left(J_{E_{1}} x^{*}, J_{E_{2}} y^{*}\right)\right\rangle \\
& \leq 0 .
\end{aligned}
$$

Finally, from (3.33), we have $\Theta_{n+1}^{*} \leq\left(1-\alpha_{n}\right) \Theta_{n}^{*}+\alpha_{n} \Lambda_{n+1}$. Therefore, from (3.48) and Lemma 2.6, we conclude that $\left(\Theta_{n}^{*}\right)$ converges to zero as $n \rightarrow \infty$. That is, $\phi\left(x^{*}, x_{n}\right) \rightarrow 0$ and $\phi\left(y^{*}, y_{n}\right) \rightarrow 0$ as $n \rightarrow \infty$. Hence by Lemma 2.2 , we have $\left(x_{n}\right)$ and $\left(y_{n}\right)$ converges to $x^{*}$ and $y^{*}$, respectively.

Case II. Assume that there exists a subsequence $\left(\Theta_{n_{i}}^{*}\right)$ of $\left(\Theta_{n}^{*}\right)$ such that $\Theta_{n_{i}}^{*}<\Theta_{n_{i}+1}^{*}$ for all $i \geq 0$. Then in view of Lemma 2.7, we can define a nondecreasing sequence $\left(m_{k}\right) \subset \mathbb{N}$ such that $m_{k} \rightarrow \infty$ as $k \rightarrow \infty$ and

$$
\Theta_{m_{k}}^{*} \leq \Theta_{m_{k}+1}^{*} \quad \text { and } \quad \Theta_{k}^{*} \leq \Theta_{m_{k}+1}^{*}
$$

for all $k \in \mathbb{N}$. Following similar steps as in Case I, we derive

$$
\limsup _{k \rightarrow \infty} \Lambda_{m_{k}+1} \leq 0 .
$$

From (3.33) and (3.49), we obtain $\alpha_{m_{k}} \Theta_{m_{k}+1}^{*} \leq \alpha_{m_{k}} \Lambda_{m_{k}+1}$, which reduces to $\Theta_{m_{k}+1}^{*} \leq \Lambda_{m_{k}+1}$. Taking the limit as $k \rightarrow \infty$ and using (3.50), we conclude that $\Theta_{m_{k}+1}^{*} \rightarrow 0$ as $k \rightarrow \infty$. Again from (3.49), it follows that $\Theta_{k}^{*} \rightarrow 0$ as $k \rightarrow \infty$. Therefore, $\phi\left(x^{*}, x_{k}\right) \rightarrow 0$ and $\phi\left(y^{*}, y_{k}\right) \rightarrow 0$ as $k \rightarrow \infty$. Hence by Lemma 2.2, we have $x_{k} \rightarrow x^{*}$ and $y_{k} \rightarrow y^{*}$ as $k \rightarrow \infty$.

If $u=0$ and $v=0$, then Algorithm 3.1 can be used to locate an element of the solution with the minimum norm.

Corollary 3.8. Let the Assumptions (A1) - (A5) and (B1) - (B4) hold. Then, the sequence $\left(\left(x_{n}, y_{n}\right)\right)$ generated by Algorithm 3.1 with $u=0=v$ converges strongly to the minimum norm point $\left(x^{*}, y^{*}\right) \in \Gamma$, that is, $\left(x^{*}, y^{*}\right)=\prod_{\Gamma}(0,0)$. 
Corollary 3.9. Assume that $T: E_{1} \rightarrow E_{1}^{*}$ and $S: E_{2} \rightarrow E_{2}^{*}$ are uniformly continuous and monotone mappings. Let the Assumptions (A1) - (A3), (A5) and (B1) - (B4) be satisfied. Then the sequence $\left(\left(x_{n}, y_{n}\right)\right)$ generated by Algorithm 3.1 converges strongly to $\left(x^{*}, y^{*}\right) \in \Gamma$, where $\left(x^{*}, y^{*}\right)=\prod_{\Gamma}(u, v)$.

Proof. The mappings $T$ and $S$ are pseudomonotone, hence by Lemma 3.6, $\left(x_{n}\right)$ and $\left(y_{n}\right)$ are bounded. It then follows from (3.46) and Remark 3.5 that $x \in \operatorname{VI}(C, T)$ and $y \in \mathrm{VI}(D, S)$, where $x$ and $y$ are weak cluster points of $\left(x_{n}\right)$ and $\left(y_{n}\right)$, respectively. The rest of the proof is similar to the proof of Theorem 3.7.

\section{Applications}

In this section, we apply our main result to solve the following problems: split equality zero point problem (SEZPP), common solutions of the variational inequality problem, common zeros of pseudomonotone mappings, split variational inequality problem, split zero point problem (SZPP), split equality feasibility problem (SEFP) and split feasibility problem (SFP).

\subsection{Split equality zero point problem}

If $C=E_{1}$ and $D=E_{2}$, then the SEVIP reduces to the SEZPP, which is to find $x \in T^{-1}(0)$ and $y \in S^{-1}(0)$ such that $A x=B y$, where $T^{-1}(0)=\left\{p \in E_{1}\right.$ : $0=T p\}$ and $S^{-1}(0)=\left\{q \in E_{2}: 0=S q\right\}$. Denote the solution of this problem by $\digamma=\left\{(p, q) \in E_{1} \times E_{2}: p \in T^{-1}(0), q \in S^{-1}(0)\right.$ and $\left.A p=B q\right\}$.

Corollary 4.1. Assume that $\digamma \neq \emptyset$. Let the Assumptions (A1), (A2), (A4) and (B1) - (B4) be satisfied with $C=E_{1}$ and $D=E_{2}$. Then the sequence $\left(\left(x_{n}, y_{n}\right)\right)$ generated by Algorithm 3.1 converges strongly to $\left(x^{*}, y^{*}\right) \in \digamma$, where $\left(x^{*}, y^{*}\right)=\prod_{\digamma}(u, v)$.

\subsection{Common solutions of the variational inequality problem}

Let $E=E_{1}=E_{2}=E_{3}, A=I$ and $B=I$. In this case, the SEVIP reduces to finding common solutions of two variational inequality problems for pseudomonotone mappings. Denote $\mathcal{F}=\{(p, q) \in C \times D:\langle x-p, T p\rangle \geq 0, \forall x \in C$ and $\langle y-q, S q\rangle \geq 0$, $\forall y \in D$ such that $p=q\}$.

Corollary 4.2. Assume that $\mathcal{F} \neq \emptyset$. Let the Assumptions (A1), (A3), (A4) and (B1) - (B4) be satisfied with $E=E_{1}=E_{2}=E_{3}$ and $A=I=B$. Then the sequence $\left(\left(x_{n}, y_{n}\right)\right)$ generated by Algorithm 3.1 converges strongly to $\left(x^{*}, y^{*}\right) \in \mathcal{F}$, where $\left(x^{*}, y^{*}\right)=\prod_{\mathcal{F}}(u, v)$.

\subsection{Common zeros of pseudomonotone mappings}

Let $E=E_{1}=E_{2}=E_{3}, A=I$ and $B=I$. If $C=E$ and $D=E$, then the SEVIP reduces to finding common zeros of pseudomonotone mappings. Denote $\mathcal{F}^{\prime}=\left\{(p, q) \in E \times E: p \in T^{-1}(0)\right.$ and $q \in S^{-1}(0)$ such that $\left.p=q\right\}$.

Corollary 4.3. Let the Assumptions (A1), (A4), (B1) - (B4) be satisfied with $C=D=$ $E=E_{1}=E_{2}=E_{3}$ and $A=I=B$. If $\mathcal{F}^{\prime} \neq \emptyset$, then the sequence $\left(\left(x_{n}, y_{n}\right)\right)$ generated by Algorithm 3.1 converges strongly to $\left(x^{*}, y^{*}\right) \in \mathcal{F}^{\prime}$, where $\left(x^{*}, y^{*}\right)=\prod_{\mathcal{F}^{\prime}}(u, v)$. 


\subsection{Split variational inequality problem}

If $E_{2}=E_{3}$ and $B=I$, then the SEVIP reduces to the split variational inequality problem (SVIP) which is to find $x \in V I(C, T)$ and $y \in V I(D, S)$ such that $A x=y$. Denote $\mathcal{T}=\{(p, q) \in C \times D: p \in V I(C, T), q \in V I(D, S)$ and $A p=q\}$.

Corollary 4.4. Assume that the Assumptions (A1) - (A4) and (B1) - (B4) hold with $E_{3}=E_{2}$ and $B=I$. If $\mathcal{T} \neq \emptyset$, then the sequence $\left(\left(x_{n}, y_{n}\right)\right)$ generated by Algorithm 3.1 converges strongly to $\left(x^{*}, y^{*}\right) \in \mathcal{T}$, where $\left(x^{*}, y^{*}\right)=\prod_{\mathcal{T}}(u, v)$.

\subsection{Split zero point problem}

Let $E=E_{2}=E_{3}$ and $B=I$. If $C=E$ and $D=E$, then the SEVIP reduces to the SZPP which is to find $x \in T^{-1}(0)$ and $y \in S^{-1}(0)$ such that $A x=y$. Denote $\mathcal{S}=\left\{(p, q) \in E \times E: p \in T^{-1}(0), q \in S^{-1}(0)\right.$ and $\left.A p=q\right\}$.

Corollary 4.5. Assume that the Assumptions (A1), (A2), (A4), (B1) - (B3) and (B4) with $B=I$ hold. If $\mathcal{S} \neq \emptyset$, then the sequence $\left(\left(x_{n}, y_{n}\right)\right)$ generated by Algorithm 3.1 converges strongly to $\left(x^{*}, y^{*}\right) \in \mathcal{S}$, where $\left(x^{*}, y^{*}\right)=\prod_{\mathcal{S}}(u, v)$.

Remark 4.6. (a). If $E=E_{1}=E_{2}=E_{3}, S=0, A=0$ and $B=0$, then Theorem 3.7 can be used to find solutions of variational inequality problems for uniformly continuous pseudomonotone mappings that are sequentially weakly continuous on bounded subsets of $E$ as well as for uniformly continuous monotone mappings. If in addition, we take $C=E$ and $D=E$, then Corollary 4.1 will approximate zeros of uniformly continuous pseudomonotone mappings that are sequentially weakly continuous on bounded subsets of $E$ and also zeros of uniformly continuous monotone mappings.

(b). In view of Corollary 3.9, and the discussion in this section, one can use the results of this section to find solutions of split equality zero point problem for uniformly continuous monotone mappings, common solutions of the variational inequality problem for uniformly continuous monotone mappings, common zeros of uniformly continuous monotone mappings, split variational inequality problems for uniformly continuous monotone mappings, split zero point problem for monotone mappings.

(c). The special cases of the above results can be obtained by taking $E_{1}=H_{1}$, $E_{2}=H_{2}$ and $E_{3}=H_{3}$ to be real Hilbert spaces.

Note that if $E=H$, a real Hilbert space, then $J_{E}=I$, the identity mapping on $H$, and $\Pi_{C}=P_{C}$, the metric projection onto $C$. A well known example of a uniformly continuous, monotone and hence pseudomonotone map is $I-P_{C}$. Henceforth, $E_{1}=H_{1}$, $E_{2}=H_{2}$ and $E_{3}=H_{3}$ are real Hilbert spaces, $C \subset H_{1}$ and $D \subset H_{2}$ are nonempty, closed and convex subsets. Also $A: H_{1} \rightarrow H_{3}$ and $B: H_{2} \rightarrow H_{3}$ are bounded linear mappings with adjoints $A^{*}$ and $B^{*}$, respectively, $T=I-P_{C}$ and $S=I-P_{D}$. Thus, we obtain the following applications in Hilbert spaces.

\subsection{Split equality feasibility problem}

Replacing $T$ with $I-P_{C}$ and $S$ with $I-P_{D}$, then the SEZPP reduces to the SEFP which seeks to find $x \in C$ and $y \in D$ such that $A x=B y$. Denote

$$
\Gamma^{\prime}=\{(p, q) \in C \times D: A x=B y\} .
$$


Corollary 4.7. Assume that $\Gamma^{\prime} \neq \emptyset$. Let the Assumptions (B2),(B3), (B4) be satisfied. Then the sequence $\left(\left(x_{n}, y_{n}\right)\right)$ generated by Algorithm 3.1 converges strongly to $\left(x^{*}, y^{*}\right) \in \Gamma^{\prime}$, where $\left(x^{*}, y^{*}\right)=P_{\Gamma^{\prime}}(u, v)$.

\subsection{Split feasibility problem}

Setting $T=I-P_{C}, S=I-P_{D}, H_{2}=H_{3}$ and $B=I$, the identity mapping on $H_{2}$, then the SEFP reduces to the SFP which seeks to find $x \in C$ such that $A x \in D$. This problem can also be expressed as a problem of finding $x \in C$ and $y \in D$ such that $A x=y$. Denote $\mathcal{S}^{\prime \prime}=\{(p, q) \in C \times D: A p=q\}$.

Corollary 4.8. Assume that $\mathcal{S}^{\prime \prime} \neq \emptyset$. Let the Assumptions (B2), (B3), (B4) with $B=I$ be satisfied. Then the sequence $\left(\left(x_{n}, y_{n}\right)\right)$ generated by Algorithm 3.1 with $B=I$ converges strongly to $\left(x^{*}, y^{*}\right) \in \mathcal{S}^{\prime \prime}$, where $\left(x^{*}, y^{*}\right)=P_{\mathcal{S}^{\prime \prime}}(u, v)$.

Remark 4.9. If we take $u=0$ and $v=0$, then one can obtain elements of minimum norm for all the application areas listed in this section.

\section{Numerical example}

In this section, we give a numerical example to demonstrate that the sequence $\left(z_{n}\right)=$ $\left(\left(x_{n}, y_{n}\right)\right)$ generated by Algorithm 3.1 converges to an element $z^{*}=\left(x^{*}, y^{*}\right)$ in $\Gamma$ for different initial values $z_{0}=\left(x_{0}, y_{0}\right)$.

Example 5.1. Let $\|\cdot\|$ be the norm on $\mathbb{R}^{2}$ induced by the inner product $\langle\cdot, \cdot\rangle$. Define the map $T: \mathbb{R}^{2} \rightarrow \mathbb{R}^{2}$ by $T(x, y)=\left(\frac{3}{2}+\sqrt{x^{2}+y^{2}}\right)(x-1, y)$. Assume that $\langle T(x, y),(u, v)-(x, y)\rangle \geq 0$ for all $(x, y),(u, v) \in \mathbb{R}^{2}$. Then

$$
\left(\frac{3}{2}+\sqrt{x^{2}+y^{2}}\right)\langle(x-1, y),(u-x, v-y)\rangle \geq 0,
$$

which implies that $\langle(x-1, y),(u-x, v-y)\rangle \geq 0$ for all $(x, y),(u, v) \in \mathbb{R}^{2}$. Therefore,

$$
\begin{aligned}
& \langle T(u, v),(u, v)-(x, y)\rangle=\left(\frac{3}{2}+\sqrt{u^{2}+v^{2}}\right)\langle(x-1, y),(u-x, v-y)\rangle \\
+ & \left(\frac{3}{2}+\sqrt{u^{2}+v^{2}}\right)[\langle(u-1, v),(u-x, v-y)\rangle-\langle(x-1, y),(u-x, v-y)\rangle] \\
\geq & \left(\frac{3}{2}+\sqrt{u^{2}+v^{2}}\right)\|(u-x, v-y)\|^{2} \geq 0,
\end{aligned}
$$

for all $(x, y),(u, v) \in \mathbb{R}^{2}$, showing that $T$ is pseudomonotone on $\mathbb{R}^{2}$.

Example 5.2. Let $E_{1}=E_{2}=E_{3}=\mathbb{R}^{2}$ be equipped with the usual norm. Assume that $A, B: \mathbb{R}^{2} \rightarrow \mathbb{R}^{2}$ are given by $A(x, y)=(0,3 y)$ and $B(x, y)=(2 x, 0)$ with adjoints $A^{*}(x, y)=(0,3 y)$ and $B^{*}(x, y)=(2 x, 0)$, respectively.

Let $C=\left\{(x, y) \in \mathbb{R}^{2}: \sqrt{x^{2}+y^{2}} \leq 1\right\}$ and $D=\left\{(x, y) \in \mathbb{R}^{2}: \sqrt{x^{2}+y^{2}} \leq 3\right\}$.

Let $S, T: \mathbb{R}^{2} \rightarrow \mathbb{R}^{2}$ be pseudomonotone maps defined as in Examples 2.13 and 5.1, respectively.

Then $\langle T(1,0),(x, y)-(1,0)\rangle \geq 0$ for all $(x, y) \in C,\left\langle S(0,-1),\left(x^{\prime}, y^{\prime}\right)-(0,-1)\right\rangle \geq 0$ 
for all $\left(x^{\prime}, y^{\prime}\right) \in D$ and $A(1,0)=(0,0)=B(0,-1)$, and so $((1,0),(0,-1)) \in \Gamma \neq \emptyset$. Also, let $\mu=0.9, \lambda=1$ and let

$$
\gamma_{n}= \begin{cases}\frac{\left\|A x_{n}-B y_{n}\right\|^{2}}{8\left[\left\|A^{*}\left(A x_{n}-B y_{n}\right)\right\|^{2}+\left\|B^{*}\left(A x_{n}-B y_{n}\right)\right\|^{2}\right]} & \text { if } n \in \Omega \\ \frac{1}{10000} & \text { if } n \notin \Omega .\end{cases}
$$

and $\alpha_{n}=\frac{1}{n+1}$. Thus assumptions $(\mathrm{A} 1)-(\mathrm{A} 5)$ and $(\mathrm{B} 1)-(\mathrm{B} 4)$ are satisfied. Using MATLAB, we get Figure 1 below which shows that for any choice of initial values the sequence generated by Algorithm 3.1 converges to a solution of the split equality variational inequality problem. The numerical example also shows that the convergence of the sequence is faster if the parameter $l \in(0,1)$ is closer to 1 compared to when it is closer to 0 .

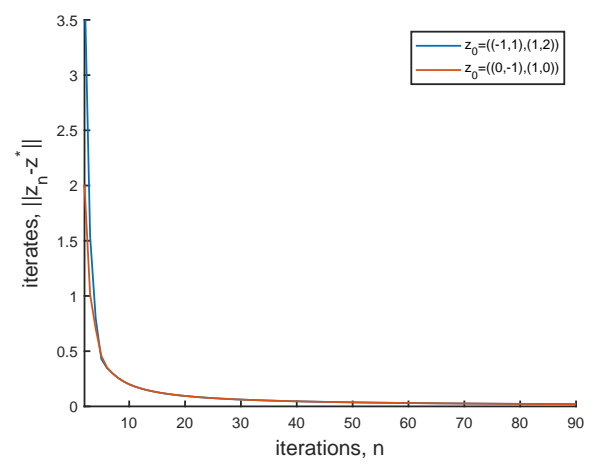

(A) Parameter $l=0.9$

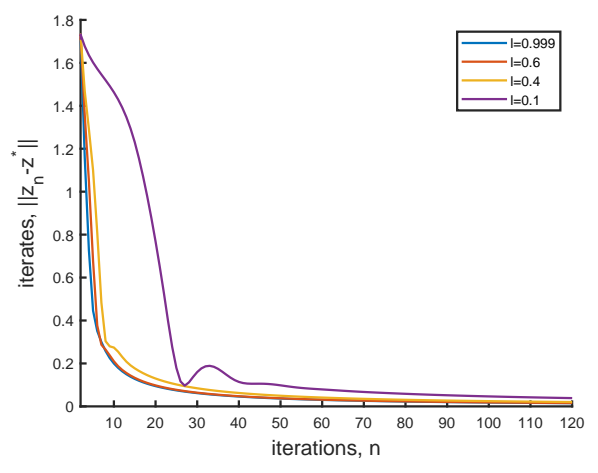

(в) $z_{0}=((0.5,0.5),(0.5,0.5))$

Figure 1. Convergence of $\left(z_{n}\right)$ to $z^{*}$

\section{Conclusion}

In this paper, we have constructed an algorithm for solving the split equality variational inequality problem in real uniformly smooth and uniformly convex Banach space settings. We also established a strong convergence theorem under the assumption that the associated mappings are uniformly continuous, pseudomonotone and sequentially weakly continuous. The algorithm does not require prior knowledge of operator norms of $A$ and $B$. We also gave some applications of our results to some problems in Banach spaces. A numerical example was also provided to demonstrate the behavior of the convergence of the proposed algorithm. Our results in this paper extend the results of Censor et al. [11], Byrne et al. [6] and Thong et al [33] to a more general SEVIP in uniformly smooth and uniformly convex Banach spaces more general than Hilbert spaces. 


\section{References}

[1] Alber, Ya., Metric and generalized projection operators in Banach spaces: Properties and Applications, In: "Theory and Applications of Nonlinear Operators of Accretive and Monotone Type" (A. G. Kartsatos Ed.), Lecture Notes in Pure and Appl. Math., Vol. 178, Dekker, New York, 1996, 15-50.

[2] Baiocchi, C., Capelo, A., Variational and Quasivariational Inequalities; Applications to Free Boundary Problems, New York, Wiley, 1984.

[3] Boikanyo, O.A., A strongly convergent algorithm for the split common fixed point problem, Appl. Math. Comput., 265(2015), 844-853.

[4] Boikanyo, O.A., Zegeye, H., The split equality fixed point problem for quasi-pseudocontractive mappings without prior knowledge of norms, Numer. Funct. Anal. Optim., 41(2020), no. 7, 759-777.

[5] Byrne, C., Iterative oblique projection onto convex sets and the split feasibility problem, Inverse Problems, 18(2002), 441-453.

[6] Byrne, C., Censor, Y., Gibali, A., Reich, S., The split common null point problem, J. Nonlinear Convex Anal., 13(2012), 759-775.

[7] Ceng, L.C., Teboulle, M., Yao, J.C., Weak convergence of an iterative method for pseudomonotone variational inequalities and fixed-point problems, J. Optim. Theory Appl., 146(2010), 19-31.

[8] Censor, Y., Bortfeld, T., Martin, B., Trofimov, A., A unified approach for inversion problems in intensity modulated radiation therapy, Phys. Med. Biol., 51(2006), 23532365 .

[9] Censor Y., Elfving, T., A multiprojection algorithm using Bregman projections in a product space, Numer. Algorithms, 8(1994), 221-239.

[10] Censor, Y., Gibali, A., Reich, S., The split variational inequality problem, The TechnionIsrael Institute of Technology, Haifa, (2010). arXiv:1009.3780.

[11] Censor, Y., Gibali, A., Reich, S., Algorithms for the split variational inequality problem, Numer. Algorithms, 59(2012), 301-323.

[12] Censor, Y., Gibali, A., Reich, S., Sabach, S., Common solutions to variational inequalities, Set-Valued Var. Anal., 20(2012), 229-247.

[13] Censor, Y., Segal, A., The split common fixed point problem for directed operators, J. Convex Anal., 16(2009), 587-600.

[14] Chang, S.-S., Joseph Lee, H.W., Chan, C.K., Wang L., Qin, L.J., Split feasibility problem for quasinonexpansive multi-valued mappings and total asymptotically strict pseudocontractive mappings, Appl. Math. Comput., 219(2013), 10416-10424.

[15] Chang, S.-S., Yao, J.-C., Kim, J.J., Yang, L., Iterative approximation to convex feasibility problems in Banach spaces, Fixed Point Theory Appl., 2007:19, Article ID 4679.

[16] Chang, S.-S., Yao, J.-C., Wen, C.-F., Yang, L., Qin, L.-J., Common zero for a finite family of monotone mappings in Hadamard spaces with applications, Mediterr. J. Math., 15(2018), Art. no. 160.

[17] Combettes, P.L., The Convex Feasibility Problem in Image Recovery, P. Hawkes (Ed.), Advances in Imaging and Electron Physics, vol. 95, Academic Press, New York, 1996, 155-270. 
[18] Eslamian, M., Fakhri, A., Split equality monotone variational inclusions and fixed point problem of set-valued operator, Acta Univ. Sapientiae. Mathematica, 9(2017), no. 1, 94-121.

[19] Fichera, G., Problemi elastostatici con vincoli unilaterali: il problema di Signorini con ambigue condizioni al contorno, Atti Acad. Naz. Lincei, Mem. Cl. Sci. Fis. Mat. Nat., Sez. I., (1964), no. 7, 91-140.

[20] Kamimura, S., Takahashi, W., Strong convergence of proximal-type algorithm in a Banach space, SIAM J. Optim., 13(2002), 938-945.

[21] Khanh, P.D., Vuong, P.T., Modified projection method for strongly pseudo-monotone variational inequalities, J. Global Optim., 58(2014), 341-350.

[22] Khobotov, E.N., Modification of the extragradient method for solving variational inequalities and certain optimization problems, USSR Comput. Math. Math. Phys., 27(1987), no. $5,120-127$.

[23] Kinderlehrer, D., Stampacchia, G., An Introduction to Variational Inequalities and Their Applications, New York: Academic Press, 1980.

[24] Maingé, P.E., Strong convergence of projected subgradient methods for nonsmooth and nonstrictly convex minimization, Set-Valued Anal., 16(2008), 899-912.

[25] Marcotte, P., Applications of Khobotov's algorithm to variational and network equilibrium problems, Info Syst Oper. Res., 29(1991), no. 4, 258-270.

[26] Mashreghi, J., Nasri, M., Forcing strong convergence of Korpelevich's method in Banach spaces with its applications in game theory, Nonlinear Anal., 72(2010), 2086-2099.

[27] Moudafi, A., Split monotone variational inclusions, J. Optim. Theory Appl., 150(2011), 275-283.

[28] Phelps, R.P., Convex Functions, Monotone Operators and Differentiability, Lecture Notes in Mathematics, vol. 1364, 2nd edn., Springer Verlag, Berlin, 1993.

[29] Shahzad, S., Zegeye, H., Convergence theorems of common solutions for fixed point, variational inequality and equilibrium problems, J. Nonlinear Var. Anal., 3(2019), no. 2, 189-203.

[30] Shehu, Y., Dong, Q.-L., Jiang, D., Single projection method for pseudo-monotone variational inequality in Hilbert spaces, Optimization, 68(2019), 385-409.

[31] Stampacchia, G., Formes bilinéaires coercitives sur les ensemble convexes, C.R. Acad. Sci. Paris., 258(1964), 4413-4416.

[32] Takahashi, W., Nonlinear Functional Analysis, Kindikagaku, Tokyo, 1988.

[33] Thong, D.V., Shehu, Y., Iyiola, O.S., A new iterative method for solving pseudomonotone variational inequalities with non-Lipschitz operators, Comput. Appl. Math., 39(2020), no. 2, paper no. 108, $24 \mathrm{pp}$.

[34] Vuong, P.T., Shehu, Y., Convergence of an extragradient-type method for variational inequality with applications to optimal control problems, Numer. Algorithms, 81(2019), 269-291.

[35] Wang, F., Xu, H.K., Cyclic algorithms for split feasibility problems in Hilbert spaces, Nonlinear Anal., 74(2011), 4105-4111.

[36] Wega, G.B., Zegeye, H., Convergence results of Forward-Backward method for a zero of the sum of maximally monotone mappings in Banach spaces, Comp. Appl. Math. 39, Article no. 223 (2020). 
[37] Xu, H.K., Another control condition in an iterative method for nonexpansive mappings, Bull. Aust. Math. Soc., 65(2002), 109-113.

[38] Yao Y., Postolache, M., Iterative methods for pseudo-monotone variational inequalities and fixed-point problems, J. Optim. Theory Appl., 155(2012), 273-287.

[39] Zalinescu, C., Convex Analysis in General Vector Spaces, World Scientific, River Edge, 2002.

[40] Zegeye, H., Strong convergence theorems for split equality fixed point problems of $\eta$ demimetric in Banach spaces, DCDIS Ser. B Appl. Algor., 26(2019), 269-288.

[41] Zegeye, H., Shahzad, N., Approximating common solution of variational inequality problems for two monotone mappings in Banach spaces, Optim. Lett., 5(2011), no. 4, 691-704.

Oganeditse A. Boikanyo

Botswana International University of Science and Technology,

Department of Mathematics and Statistical Sciences,

Private Bag 16, Palapye, Botswana

e-mail: boikanyoa@gmail.com

Habtu Zegeye

Botswana International University of Science and Technology,

Department of Mathematics and Statistical Sciences,

Private Bag 16, Palapye, Botswana

e-mail: habtuzh@yahoo.com 